\title{
Percepción del terror peruano entre 1900 y 1910: abordajes periodístico, político y religioso para el análisis de Cuentos malévolos de Clemente Palma
}

\author{
Perception of Peruvian Terror Between 1900 and 1910: Journalistic, Political and Religious \\ Approaches to the Analysis of Malevolent Tales of Clemente Palma
}

Jesús Miguel Delgado Del Aguila' (iD

\author{
Cómo citar \\ Delgado Del Aguila, J. M. (2021). Percepción del terror peruano entre 1900 y 1910: abordajes periodístico, político y religioso para \\ el análisis de Cuentos malévolos de Clemente Palma. Socialium, 5(1), 86-110. https://doi.org/10.26490/uncp.sl.2021.5.1.739
}

${ }^{1}$ Magíster en Literatura con mención en Estudios Culturales, Licenciado en Literatura, investigador Concytec, Universidad Nacional Mayor de San Marcos, Lima, Perú.

jesus.delgado@unmsm.edu.pe Google Scholar

Arbitrado por pares ciegos

Recibido: 5/10/2020

Aceptado: $20 / 11 / 20$

\section{RESUMEN}

Esta investigación tiene como objetivo la reconstrucción del concepto de terror en la primera década del siglo XX. La delimitación temporal se debe a que en ese lapso se publicó un compendio de relatos de tópico terrorífico, intitulado Cuentos malévolos (1904), del escritor peruano Clemente Palma. Para lograr la configuración semántica del término aludido, se recurre a la documentación de fuentes periodísticas de ese entorno (como El Comercio, La Prensa, Variedades, entre otros), para respaldar la percepción asumida del mismo. A través de la confrontación de estos discursos, es notoria la influencia que recibe el autor por parte de las temáticas derivadas, como la asociación del terror con la criminalidad o el oscurantismo que se desenvuelven por personas desequilibradas. Igualmente, la ideología y la filosofía que se extraen se vinculan con el ateísmo y todo lo que critica y cuestiona los dogmas de la religión judeocristiana.

Palabras clave: terror; Perú; siglo XX; periodismo; religión.

\section{ABSTRACT}

This paper aims to reconstruct the concept of terror in the first decade of the twentieth century. The temporal delimitation is due to the fact that in that period a compendium of horror stories was published, entitled Malevolent Tales (1904), of the Peruvian writer Clemente Palma. To achieve the semantic configuration of the aforementioned term, we resort to the documentation of journalistic sources of that environment (such as The Trade, The Press, Varieties, among others), to support the perception assumed of it. Through the confrontation of these discourses, the influence that the author receives on the part of the derived themes, such as the association of terror with criminality or the obscurantism developed by unbalanced people, is notorious. Likewise, the ideology and philosophy that are extracted are linked to atheism and everything that criticizes and questions the dogmas of the Judeo-Christian religion.

Keywords: terror; Peru; twentieth century; journalism; religion. 


\section{Introducción}

Este estudio tiene como propósito el hallazgo de la percepción del terror desde la visión de inicios del siglo XX, periodo en el que se publicó Cuentos malévolos (1904) de Clemente Palma. Por esa razón, se recurre a la documentación periodística para corroborar la recepción que tuvo este compendio de relatos.

En una primera instancia, se determinan los discursos que están asociados con el tópico del terror, que coinciden con el contenido, los encabezados y los títulos de las noticias, los artículos o las creaciones literarias. Por otra parte, las fuentes que se corroboran para la obtención de esta información son los periódicos La Prensa, El Comercio, El Peruano, Los Parias, La Campana, El Libre Pensamiento y la revista Variedades (esta última fue dirigida por el autor de la obra indagada).

En una segunda oportunidad, se hace alusión al abordaje político que se aprecia en el Perú, como también las influencias que recibe de otros países. Estas se caracterizan por las confrontaciones bélicas por las cuales atraviesan muchos de los territorios. En ese sentido, el terror se configura como una consecuencia de la etapa crítica en la que viven los ciudadanos por la suposición y la intranquilidad de que podrían terminar como víctimas inesperadas.

Para finalizar, se toma en cuenta la religión por los dogmas derivados, que se encuentran en un momento de cuestionamiento para prevalecer propuestas racionales y ateístas. Considérese que los relatos que comprenden la obra de Palma están respaldados por esa ideología que critica la creencia instaurada en los fieles desde siglos remotos.

\section{Métodos}

El método extrapolado para esta investigación se ciñe a la documentación cualitativa, en la que se conseguirán discursos concomitantes de los registros de la prensa en cuanto a tres áreas identificables: periodismo, político-histórica y religiosa. Este procedimiento es selectivo y excluyente, debido a que se retomarán elementos que se asocian con el terror de ese periodo. A la vez, la obtención de información se someterá a un método analítico, ya que, a partir de los resultados extraídos, se erigirá un metaanálisis orientado a la consolidación taxonómica del concepto de terror y la corroboración epistemológica con Cuentos malévolos de Clemente Palma. 


\section{Resultado}

Los resultados se han extraído de la confrontación cualitativa con los diarios de La Prensa, EI Comercio, El Peruano, Los Parias, La Campana, El Libre Pensamiento y la revista Variedades de la primera década del siglo XX, que han sido clasificados por temas: periodismo, político-histórica y religiosa. Estos se explicarán a continuación.

\section{Registro periodístico del terror}

En esta ocasión, las referencias de utilidad son las noticias publicadas en los diarios durante el primer decenio del siglo XX, de las que se infieren diez tópicos apoteósicos: la volición publicitaria, el desarrollo de los deportes, los problemas en la salud, la naturaleza y la sociedad, la percepción de la sociedad sobre el crimen, los crímenes micro y macro, lo místico y dos noticias vinculadas directamente con Cuentos malévolos.

El primer tema, la pretensión publicitaria, es notorio con los anuncios que se indican en los diarios, que comúnmente irán acompañados con fotografías, imágenes y hasta caricaturas en torno a la venta de artefactos y medicinas, la exhibición de vestidos y atuendos para mujeres en la sección "Modas" (Variedades, 1908-1910), los lugares en los que se efectúan sastrerías, telegramas, centros de suscripciones, piezas musicales, etc. Muchas veces, estos anuncios están orientados a personas de la clase media-alta, al igual que a sus actividades sociales, como ocurre con la realización de las fiestas (Castro Oyanguren, 2 de febrero de 1904). Asimismo, se observa algo particular en la revista Variedades, de Clemente Palma: emplea su cargo como director para promocionar y promover la venta de su libro al final de cada edición de su revista. Esto se corrobora en el siguiente anuncio: “Cuentos malévolos por Clemente Palma (ed. de Barcelona) con prólogo de Miguel de Unamuno. El tomo empastado se vende al precio de dos soles en las librerías de Rosa y de Gil” (p. 736).

El segundo, basado en el desarrollo de los deportes, alude principalmente a la corrida de toros (Miró Quesada, 9 de enero de 1900), como también a la hípica, que son expuestas en el apartado deportivo de la revista Variedades (1908-1910).

El tercero, referido a los problemas en la salud, se enfoca en su mayoría en deficiencias que degeneran el cuerpo humano. Por ejemplo, hay un artículo de una noticia, publicado en La Prensa (1904), titulado “iHorror!", propugnado por el descubrimiento científico de que las personas ebrias transmiten enfermedades a sus hijos, a causa del debilitamiento del organismo al que se someten a medida que consumen estas bebidas. Lo mismo acontece con otros titulares de noticias, como "Asesinos", "iVeneno!" o "Verdugos", de los que se infiere las repercusiones que tuvo gente fumadora o en estado etílico con respecto a sus progenitores. De modo semejante, la lepra se 
difundió masivamente. Esta se revela en la nota periodística "La lepra y los leprosos (algunos casos típicos de lepra)" de La Prensa (12 de julio de 1905). En esta, se considera que este tipo de enfermedad es una amenaza propagada en el Callao. Otro padecimiento más que se desenvuelve es la tuberculosis. Verbigracia, en "El día. Contra la tuberculosis" de El Comercio (9 de enero de 1900), se coloca un índice de mortandad, producto de ese malestar; junto con "Cuestiones médicas. La alimentación de los tuberculosos. Las grasas. La glicerina. El azúcar" de La Prensa (23 de septiembre de 1903), en el que se explica científicamente esta deficiencia y las maneras de subsanarla. Por ejemplo, este tópico es tomado por Palma en "Las vampiras" (2006 [1904], pp. 328-323). Manteniendo una temática similar, el 26 de septiembre de 1903 remite a las enfermedades que adquiere el hombre, como la hemofilia. Como contraparte, en el diario La Prensa, existen constantes menciones sobre las formas de combatir cualquier estado de salud deteriorable, ya sea físico o psicológico. En una ocasión, esto acaece por medio de la innovación y la experimentación en las ciencias, que son exhibidas en anuncios publicitarios, como "No más canas" (23 de enero de 1904), o el tratamiento del herpes y el cáncer en la sección del periódico titulada "Cuestiones médicas" (24 de enero de 1904), al igual que las modalidades para contrarrestar la peste bubónica en Lima, que se manifiesta desde el 6 de febrero de 1904 en lo sucesivo. Esta peculiaridad se cerciora en una noticia posterior: "El caso sospechoso de peste bubónica" (4 de febrero de 1905).

El cuarto tópico es avalado por los problemas generados por la naturaleza, como las inundaciones en Tarma (Ulloa Cisneros, 5 de febrero de 1905), los temblores (Castro Oyanguren, 3 de diciembre de 1904) que producen terror a las personas, junto con los efectos de intranquilidad y angustia. Por ejemplo, en La Prensa (1904), se registra la noticia "A última hora. Temblor terrible. Pánico general", en la que se detallan las repercusiones provocadas por un temblor en distintos distritos de Lima, como también lugares específicos afectados, como la Catedral. No obstante, lo enjundioso es corroborar la reacción concomitante de las personas que vivieron este acontecimiento:

La madrugada, con tan inesperado suceso, ha dado a Lima, aspecto bastante extraño.

En el momento mismo del temblor, cualquier transeúnte trasnochado que hubiera conservado la serenidad de espíritu suficiente para constituirse en espectador tranquilo del fenómeno sísmico, se hubiera espantado de seguro, ya que no de la trepidación violenta de la tierra, del inusitado vocerío que hacía estremecer el interior de todos los hogares.

Los vecinos y las vecinas se echaron a la calle hasta en camisa, y era de ver el recogimiento angustioso con que caían de rodillas implorando el aplacamiento de las iras divinas. 
En los barrios populares, las familias trabajadoras han llenado materialmente las calles debatiéndose en ellas en exclamaciones constantes.

Puede asegurarse que no ha habido vecino de Lima, capaz de resistir desde el lecho, con estoica tranquilidad, el poco frecuente furor con que el fenómeno nos ha azotado esta vez.

Pasados los primeros instantes, las calles han cobrado mucha vida con el ir y venir de carruajes, de transeúntes ansiosos de recorrer la población o de miembros de familia que marchaban en pos de noticias de parientes y amigos.

El servicio telefónico no ha podido darse abasto para los innumerables suscritores que pedían conexión.

Hasta esta hora en que LA PRENSA [sic] vuelve a ver la luz de hoy, el tráfico en las calles es grande y las noticias que cada uno lleva son más o menos abultadas (Castro Oyanguren, 1904).

El quinto tema, respaldado por los problemas nacionales acaecidos en la sociedad, es notorio a través del terror percibido por las pérdidas económicas y el cierre de compañías bancarias, el mismo que es predominante en el apartado "Patio de Máquinas", dentro del artículo "El pánico de New York" (7 de agosto), escrito por Pierpont Morgan, en el diario La Prensa (23 de septiembre de 1903). Otro caso se localiza en "La visita de cárceles" (15 de enero de 1905), en el que se menciona la renovación de las leyes que competen a los sentenciados, a la vez que se desarrolla un número estadístico de algunos implicados, como la cantidad de enjuiciados en Lima, Huarochirí y Canta, junto con el fuero militar. Adicionalmente, se designan los oficios que cumplen quienes están en las cárceles, como laborar en el taller de zapatería, los sastres, los aparadores, los plateros, los carpinteros y la herrería. Entre otras noticias, se ubican las del 4 de febrero de 1905: “El cadáver de Dulanto abandonado. No existe Morgue en el Callao", "Un caso inconcebible (de nuestro corresponsal)", critica en torno a la inexistencia de un lugar específico para colocar a un occiso, y "Los que mueren de hambre. Un asesinato", que registra el instante en el que dos indígenas fueron hallados muertos por falta de alimentación.

La sexta variante se enfoca en la consideración que posee la sociedad sobre el crimen, como, verbigracia, en la noticia "Asesinos y falsarios", en la que existe una conformación neurálgica en torno a los homicidas. Al respecto, el siguiente fragmento acerca del acontecimiento explica la concepción que se adopta en ese momento: 
Algún día se han de llamar a las cosas por sus nombres; algún día se han de desterrar estos procedimientos hipócritas e indignos de cubrir con las flores de la lisonja y del disimulo a quien no tiene derecho de demandar la complacencia de las gentes honradas. Los asesinos de ayer, los que esgrimieron sus armas para matar y herir a varios hijos del pueblo, son los mismos que, procediendo con iniquidad y bajeza, han tejido una historia de calumnias y embustes para disculpar su actitud (Castro Oyanguren, 27 de junio de 1904).

Con este discurso, se justifica el accionar de los asesinos, quienes se encuentran psicológicamente mal, siendo estos culpables de que la sociedad no pueda defenderse, nadie los cura. Otras propuestas fundamentadas, desde el género del cuento, en las que el tema primordial son la muerte o el suicidio, se aprecian en relatos breves de La Prensa (24 de marzo de 1904), como "En broma" o "Quería morir".

Antes de pasar al séptimo y el octavo tópicos, he estructurado la representación mediante microcrímenes (casos en concreto, como asaltos, asesinatos, etc.) y macrocrímenes (delitos que involucran al Gobierno y el Estado por su mal desempeño).

El séptimo tema, referido a los microcrímenes, que se afianzan por acontecimientos que no tienen repercusiones sociales diacrónicas, más que en un ámbito cerrado, como el familiar. A lo largo del diario La Prensa, la presencia de la criminalidad (robos) es notoria, pues prevalecen noticias que aluden a hurtos con una redacción extensa, casi literaria, y con singularidades de lo que va ocurriendo, por ejemplo, en "El suceso desgraciado de hoy. Escena trágica en la casa Dammert", se revelan situaciones particulares de robo, criminalidad y detención policial. También, se patentiza otras notas periodísticas, como "Crónica sangrienta" (Ulloa Cisneros, 5 de julio de 1905) y "Un enterrado vivo. Salvado 71 horas después" (17 de marzo de 1904). Del mismo modo, se detecta la muerte autogenerada de Adelsward (Castro Oyanguren, 12 de febrero de 1904), al igual que la noticia del "Suicidio en la Maisón de Santé. Un enfermo que se ahorca" (Ulloa Cisneros, 22 de mayo de 1905), en la que se registra a un occiso natural de Toulousse (Francia), quien fenece ahorcado por la desolación que pasaba en el hospital. "Los desesperados de la vida. Intento de suicidio en el hotel 'Central'” (Ulloa Cisneros, 30 de enero de 1905) alega la ocasión en la que el italiano Fabro, hospedado en el Hotel Central de Lima, quiso matarse con una acuchillada, debido a la miseria y el infortunio que le agobiaban. "Los últimos suicidios" detalla cuatro muertes autoprovocadas sin motivos específicos, aunque la nota termina de la siguiente manera: "Las causas determinantes de estos suicidios no han sido puestas bien en claro todavía, y se juzga generalmente que lo hayan sido el cansancio y desengaño de la existencia" (Palma, 26 de junio de 1909, p. 393). 
Surge la noticia de una mujer extraviada el 22 de julio de 1904 en La Prensa, junto con el de otra titulada "Horrible tragedia. Una madre que come a su hija. Denuncia original", en la que se observa una parte de la descripción de los hechos criminales y el estado psicológico alterado:

Cuando lograron arrebatarla de las manos de la loca, ya estaba muerta; le había arrancado a mordizcos [sic] el pulgar de la mano derecha, las extremidades de cuatro dedos de la mano izquierda, un carrillo, la nariz y la oreja izquierda [...]. La loca fué [sic] conducida a la comisaría más próxima. Por todo el camino iba gritando a grandes voces: "- iQuieren quitarme a mi hija!

¡Quieren quitarme a mi hija! ¡Prefiero comérmela! Dádmela [sic], dádmela, dádmela!" (Castro Oyanguren, 29 de agosto de 1904).

Las noticias publicadas en secuencia se relatan en La Prensa con los títulos de "Robo y persecución" (16 de febrero de 1905), "Crimen por celos. Drama pasional. Dos puñaladas. Captura del criminal" (18 de febrero de 1905), "Asalto y robo en la Magdalena Vieja" (25 de febrero de 1905), "Escena sangrienta. Una puñalada" (28 de febrero de 1905), "Captura de un bandolero. Sus hazañas" (28 de febrero de 1905) y "Accidente desgraciado. Un caballero lesionado" (28 de febrero de 1905), "Un guardia criminal en la comisaría del $6 .^{\circ}$. Captura" (1 de marzo de 1905), "El fratricida. Narración verdadera" (1 de marzo de 1905), "Caso de locura. En un calabozo de la Intendencia. Comiéndose a un perro" (3 de marzo de 1905), "Los crímenes en el campo. Mujer atropellada" (3 de marzo de 1905), "Riña sangrienta. Tres heridas" (6 de marzo de 1905), "Un ahogado. La desgracia de ayer" (6 de marzo de 1905) y "Riña de obreros. Una puñalada (de nuestro corresponsal en el Callao)" (6 de marzo de 1905), junto con la publicada en Variedades, "Crimen por celos" (25 de septiembre de 1909, p. 711). La última noticia alude a un tal Leonardo García Bedoya, quien es el culpable de apuñalar a María Guadalupe Lara por celos, para que después sea derivada al hospital.

El octavo tópico, referido a los macrocrímenes, aborda los acontecimientos que involucran al Estado o las fuerzas del orden por algún delito cometido, con repercusiones notorias en la sociedad. Este carácter se cerciora en las notas periodísticas de "El robo en el Correo" (Castro Oyanguren, 28 de enero de 1904), "Un guardia criminal en la comisaría del 6. . Captura” (Ulloa Cisneros, 1 de marzo de 1905), "El fusilamiento de Ferrer" (Palma, 15 de octubre de 1909, pp. 775-776), "Hallazgo de explosivos. Dinamita y bombas frente a la Intendencia. Sensación en el barrio" (Ulloa Cisneros, 21 de febrero de 1905), "Maltratos a una mujer. Ataque a la policía. Un guardia herido” (Ulloa Cisneros, 20 de junio de 1905) y "El crimen Roccatagliata" (Palma, 25 de septiembre de 1909, p. 711), que consisten en la aparición de nuevas pruebas de los criminales Casquero y Timorán, quienes 
asesinaban por placer y sin causas justificadas. También, se detecta "Una cuchillada mortal. Crimen por idiotismo. Capturas. Atentado criminal en la Intendencia" (Ulloa Cisneros, 26 de abril de 1905), en la que se retiene al criminal. No obstante, se desconocen los motivos del hecho que incitaron el asesinato; y las noticias "Las víctimas de los accidentes" y "Horrores en el Acre" de Los Parias (octubre de 1905), que recurren a delitos acaecidos en el Perú.

El noveno, relacionado con lo místico, se evidencia en noticias de El Comercio, La Prensa y Variedades. Verbigracia, una de las primeras notas periodísticas de inicios del siglo XX está destinada al dios Huiracocha, la cual se titula "Inserciones. La conferencia del doctor patrón", en la que se aborda la concepción de temor:

Las creencias primitivas de los súmeros [sic] eran hijas del temor que les inspiraban los malos espíritus esparcidos en el mundo. Eran de formas horrorosas y solo vivían pensando en dañar a los hombres. Otros espíritus eran, por el contrario, de naturaleza buena y protectores de la humanidad, en cuyo beneficio luchaban contra los primeros. Todos los malos demonios estaban bajo el poder y dirección de uno de superior categoría, llamado "Espíritu del cielo"; y los buenos demonios obedecían también a otro de más alto rango, denominado "Espíritu de la tierra" (Miró Quesada, 10 de enero de 1900).

Este tipo de noticias se sigue considerando en otros diarios, como ocurre con La Prensa (6 de marzo de 1904), que detalla un reporte de la telepatía, al referirse a un estudio sobre la forma de comunicarse a distancia. Asimismo, se localiza la noticia "El brujo de la calle de Saloon", en la que se corrobora un encuentro particular en la casa del difunto Luis V. Vera: "También ha hallado un paquete de pelo de diversos colores, muñecos de trapo y paja, cintas, azufre en polvo, imán en herradura, alfileres, trapos y papeles manchados de sangre, sedazo [sic] con papelitos doblados; bujías de mechas engomadas, alumbre, óxido de fierro, orquillas [sic], espinas de pescado y vegetales" (Castro Oyanguren, 14 de abril de 1904). Igualmente, se incluye la fijación hacia una momia:

La momia estaba suspendida de una soga en una esquina del cuarto, tapada con un transparente; Vera quitaba el polvo todos los días á [sic] su momia y la cuidaba con gran solicitud. Por la noche jamás dormía en el mismo cuarto, sino que cerraba la puerta, encerrando la momia y durmiendo él en la puerta cuidándola (Castro Oyanguren, 14 de abril de 1904). 
Por otro lado, en la sección “Cuestiones médicas” (Castro Oyanguren, 25 de septiembre de 1904), se distinguen resurrecciones parciales y totales, que se generan por una catástrofe desde el corazón, además de colocar como sucesos los acontecidos a Tuffier y Starling. A su vez, hay publicaciones del 11 de abril de 1908 en Variedades en las que se aprecian títulos de cuentos incorporados, tales como "Almas que emigran", "Otras almas" y "Los habitantes de Marte", junto con "El espiritismo y la enquete [sic] de "Le Matin" (Neluz, 30 de mayo de 1908), en el que se evidencia el misticismo, la práctica de los hechiceros y los médiums. De esta fuente, en el apartado denominado "Curiosidades y recortes", se publica "En el mundo de las hadas y los duendes" (Palma, 13 de febrero de 1909, pp. 1623-1624), en el que se mencionan personajes fantásticos heterogéneos, como el silfo, el gnomo, el duende, el hada y los goblins, quienes estarían poblando la mayor parte de Europa. Otro artículo, "La muerte" (Morales de la Torre, 15 de mayo de 1909, p. 259), explica con amplitud el significado de la muerte, desde lo filosófico hasta lo social. También, se identifica un texto del mismo autor, titulado "Almas mudas" (Palma, 30 de octubre de 1909, p. 838), en el que se justifica la posibilidad de movimiento de lo inanimado (la inercia de los cuerpos inorgánicos): la fecha coincide con la nota "Un horrible experimento chino", dentro de la sección "Curiosidades y recortes", que exterioriza el hábito de un señor basado en introducirse culebras pequeñas en la nariz y expulsarlas por la boca. Encima, en una foto del apartado "Chirigotas", que se denomina "Espiritismo" (Palma, 10 de septiembre de 1910, p. 1137), aparece la imagen de una persona tapada totalmente con una túnica blanca, sin revelar el rostro, alrededor de señores que visten con ternos y que se muestran sorprendidos. Adicionalmente, se observa la sección "La esfera de cristal" de Variedades y las persistentes consideraciones del porvenir.

Para finalizar, el décimo tópico aborda dos noticias vinculadas directamente con Cuentos malévolos, uno enfoca en el tema de la desaparición del oro, mientras que el otro trata el terror que conllevaba la idea de la llegada del cometa Halley a la Tierra. Sobre el primer enlace, hay un texto titulado "EI oro que huye", similar al relato de Palma, "La última rubia" (2006 [1904], pp. 239-247), que desarrolla la temática de la extinción del oro:

La conversación de la semana ha sido el tesoro de Orueta descubierto al fin, después de una fatigosa campaña de cerrajería contra una pertinaz caja de fierro que se negaba á [sic] mostrar el misterio de su contenido. En la tarde del sábado pasado la tenacidad curiosa, febril, de jueces, cónsules, interventores, periodistas y mecánicos pudo ser satisfecha: la caja de fierro, el famoso receptáculo de los tesoros de un avaro asesinado oscuramente, abrió su boca y habló con ese elocuente lenguaje de las cosas. Allí en los compartimentos complicados de su mecanismo interior estaba 
la riqueza que la imaginación popular equiparaba á [sic] los legendarios tesoros de Creso y de los sultanes y los ladrones de las Mil y una noches [sic]. Y en efecto medio millón de soles en libras esterlinas dormían encarcelados en bolsas que, con mano convulsiva y bajo el brillo de una mirada sensual, atara el desgraciado prestamista. Otro medio millón de soles había en cenizas, en restos mortuorios, en huesos que en un tiempo tuvieron vida y fueron carne sólida de fortuna real: nos referimos á [sic] los fajos de billetes fiscales que en ya lejanas épocas circularon en el país. El prestamista los guardaba. ¿como [sic] un recuerdo ó [sic] como una esperanza? Dificil [sic] es saberlo. Hombre burdo, sin cultura ni alcances, acaso creía que en algún futuro, próximo ó [sic] remoto, esos papeluchos volverían á [sic] ser nervio de riqueza. En bonos de la deuda interna también tenía Orueta inmensa fortuna, y en acciones de la empresa del agua... Un delirio de oro. $Y$ en joyas, en prendas, en sueldos empeñados, en cédulas, en antigüedades, ... [sic] Oro más oro!... [sic] Y aún no ha terminado el inventario.

El pobre avaro tenía la monomanía de no movilizar su dinero. Chapado á [sic] la antigua creía que el mejor guardián de su dinero es uno mismo. Las empresas fracasan, los bancos quiebran: las cajas de hierro son las únicas que saber ser fieles y leales y resguardan el oro de las contingencias fatales, de la maldad y de la picardía. En oro, en plata, en joyas y prendas de plazo vencido tenía Orueta más de un millón de soles, que colocados en establecimientos de crédito del país le habrían redituado enormes sumas. Pero ¿valía la pena arriesgarlas aquí ó [sic] en los bancos europeos? Orueta juzgaba que no. Sabía todo lo que contribuyen los intereses á [sic] incrementar un capital; pudo en diez, en quince años duplicar su tesoro monetario por la acumulación de intereses, pero ello le habría exigido el inmenso sacrifico [sic] de su sensualidad de avaro. No acariciar su oro, no hundir en él sus manos ardorosas, no pasear sus miradas sobre las doradas ondas.... [sic] Eso era superior á [sic] sus fuerzas. Y así como un padre sigue con íntima delectación el crecimiento de sus hijos y va puliendo el corazón y el cerebro de sus retoños, así Orueta seguía, día á [sic] día, centavo á [sic] centavo, sol á [sic] sol, libra á [sic] libra el aumento paulatino de su oro tan bello y tan amado. Pagaba más que cualquier padre en la educación y en los placeres de un hijo, el goce espasmódico de educar y acariciar á [sic] ese hijo de cincuenta años de trabajo rudo, desconfiado y sordo: su oro. Si [sic], esa renta que no quiso obtener de su dinero, [sic] era el sacrificio que hacía al lujurioso placer de 
celar todas las noches á [sic] la querida fortuna y dormir con ella. ¿Cuales [sic] serían los ensueños de Orueta? El pobre hombre ha sido asesinado una noche. Nadie le ha llorado. Nadie deplora su muerte. La querida Fortuna se va con otros: del oscuro zalquizamí [sic] irá á [sic] gozar del sol en algún villorio [sic] vizcaino [sic]. Todo ese oro que simboliza miserias, amarguras, derrumbe de fortunas privadas, joyas ancestrales, honores, recuerdos de amor y de vanidad, todo eso huye de la morada triste del Arzobispo [sic] ansioso de ver luz, de moverse, de circular y de vivir... Y todo eso se irá lejos en las escarcelas de dos ancianas. Pero se sabe que Orueta fue hombre, aunque no lo pareciera, y que tuvo amoríos fugaces, pasiones de varon [sic] porque alguna vez fue joven y alguna vez fue viejo. Asegúrase [sic] que alguna vez sus relaciones rápidas y mezquinas tuvieron consecuencias...... [sic] y que existe por ahí un chiquillo en la miseria, hijo del avaro. Si ello se confirmara [sic] el viaje de las hermanas de Orueta sería menos fructuoso de lo que ellas han supuesto. Publicamos una nutrida iuformación [sic] gráfica de los detalles de la apertura de la caja de caudales del difunto prestamista (Palma, 17 de septiembre de 1910, pp. 1156-1159).

La segunda conexión se establece con el hallazgo de la noticia "El cometa Halley", que es referida de la siguiente manera:

Es motivo de vehemente preocupación entre los sabios y astrónomos europeos y americanos el paso del cometa de Halley, en mayo del año en curso, por la órbita de la tierra [sic]. Los cometas han producido en todas las épocas el espanto de los pobres moradores de este planeta. Este cometa que hoy nos amenaza hace su aparición en períodos [sic] de más de cincuenta años, aumentando [sic] la velocidad de su movimiento de traslación á [sic] medida que se acerca al sol [sic] ó [sic] sea en su afelio. En el perihelio ó [sic] sea su mayor distancia del sol [sic], su velocidad es de dos á [sic] tres metros por segundo y en cambio en su afelio es de más de diez millones de kilómetros al día.

Tiene una cola gaseosa que se prolonga hasta más de cuarenta millones de kilómetros. Esa maldita cola es la que podría, según los sabios, fastidiarnos por un rato. Esta vez es seguro que a cabeza o núcleo del cometa no chocará con la tierra [sic]; esta pasará tranquilamente la sección de su órbita por la que atravesará el cometa algunos días antes. Pero al seguir este su rumbo y la tierra [sic] el suyo habrá un momento de unas cuantas horas en que la tierra [sic] será alcanzada por la 
extremidad de la cola del cometa, del mismo modo que una nube que el aire arrastra en el cielo alcanza y envuelve uno de esos globos con gas que se escapa de las manos de un niño. Publicamos un grabado que dá [sic] la explicación gráfica del fenómeno. Como se vé [sic] la tierra [sic] pasará el punto de cruce con la trayectoria del cometa a principios de mayo; ese mismo punto lo cruzará el cometa, [sic] alejándose de la tierra [sic], varios días después. Pero su cola que como es sabido, siempre está en sentido opuesto al sol [sic], es muy larga y, antes de que la tierra [sic] haya logrado ponerse a más de cuarenta millones de leguas, envolverá en su fluido a nuestro pobre planeta. ¿’Pero qué peligro hay en ello? Realmente no habría por que [sic] alarmarse si no fuera porque el análisis espectral que se está haciendo revela que la sustancia gaseosa de ese apache celeste está compuesta de gas cianógeno que es como si dijéramos ácido prúsico evaporado. Es el sistema moderno de los apaches de Paris [sic] que suministran cloroformo a sus víctimas para inutilizarlos y desvalijarlos a su gusto. Pero bueno será no asustarse mucho, porque lo más posible es que nada nos pase á [sic] los terráqueos [sic] por una razón muy sencilla: que la atmósfera de la tierra [sic], aunque no lo parezca, constituye una coraza formidable muy difícil de ser atravezada [sic] por rabitos más o menos malignos de los cometas. Solo hay una contra y es que el gas de la cola del cometa sea más denso que la atmósfera. Esto es lo que tratan hoy de determinar los sabios. Cualquier cosa que se averigue [sic] al respecto la pondremos en conocimiento de nuestros lectores para que vayan arreglando sus asuntos espirituales con tiempo (Palma, 26 de febrero de 1910, pp. 271-272).

Más adelante, en el artículo "Contra cometitas. Invento notable y de actualidad" (Piphan, 26 de marzo de 1910, pp. 389-390), se cuestiona de nuevo el impacto fatal que tendría el cometa Halley en la Tierra, adoptando la especulación de que no habría una consecuencia leve. Las dos noticias de este acontecimiento son muy similares con el cuento "El día trágico" (2006 [1904], pp. 344-372) de Clemente Palma.

\section{Contextualización política del Perú en torno al terror (1900-1910)}

Esta reconstrucción ha sido indagada desde las revistas Variedades y La Prensa. Con El Peruano (19001910), hay datos muy institucionales, basados en los cambios educativos, políticos y jurídicos; al igual que con La Campana (1902-1908), que aborda noticias de política. Lo mismo ocurre con el periódico Los Parias (1904-1907) al poseer, en su mayoría, referencias comunistas con reportajes dirigidos a la clase obrera. Toda esta información permite delimitar el contexto internacional con otro nacional, 
con la volición de asociar la política con la vida militarizada y clasista, tal como se demostrará en la representación del caso peruano.

Sobre el panorama político internacional, en La Prensa, se alude a información de la cultura y la historia del mundo oriental (Corea) (29 de febrero de 1904), como también en función de los anuncios de guerras, como la ruso-japonesa (12 de febrero de 1904) y la mención específica de problemas políticos de otros países (Dinamarca, Turquía, Inglaterra, Austria, Francia, Uruguay, Chile, Francia, etc.), como sucede con el conflicto entre japoneses y peruanos (14 de febrero de 1904). Además, se percibe lo acaecido en Londres con la retirada de los rusos y el temor de los japoneses al tener que exponerse a territorios minados. Con respecto a Bélgica y Alemania, se registran a las personas que resultaron heridas por un huracán. Para Italia, sobresale la disputa legal por la realización de excavaciones. Entretanto, en Rumania, se difunde la noticia de que el gabinete ha renunciado. De manera semejante, para Estados Unidos, prevalece la pretensión por construir el canal de Panamá, mientras que, para Colombia, importan las revoluciones contra el Gobierno. Esto es similar a lo que requiere Bolivia, en cuanto a la consolidación de tratados pactados con Chile (Ulloa Cisneros, 19 de enero de 1905). A ello, se añade la situación de la guerra ruso-japonesa (Ulloa Cisneros, 2 de enero de 1905), junto con la conformación del socialismo de Rusia (Ulloa Cisneros, 22 de enero de 1905). Posteriores problemas son desarrollados en el mismo periódico, como la batalla de Rusia contra Japón: en la que se documenta de las armas, la información de la guerra (Castro Oyanguren, 10 de abril de 1904) y la huelga patentizada el 22 de mayo de 1904, en el Callao, en la que se manifiesta destacablemente el tributo a personajes militares, políticos y presidentes.

En el contexto nacional, se hacen acotaciones constantes al conflicto externo de Perú y Chile en el diario La Prensa por la obtención de las ciudades de Tacna y Arica; sobre todo, en un artículo denominado "Contradicciones y expectativas" (10 de enero de 1905). No obstante, para enfatizar la política en los ciudadanos, fue indispensable contar con una posición socioeconómica alta, como también interesarse por las actualidades científicas (la radio, el aerostático o la fotografía Kodak), que se aseveraban en la revista Variedades (1908-1910), en la sección "Actualidades científicas". Todo ello se evidencia con la finalidad de poder adquirir lo que publicitaban los medios de comunicación. Por ejemplo, hay aprecio por el baile y los eventos que se realizan en los teatros destinados exclusivamente a la clase alta (La Prensa, 1905). Por un lado, de ese modo, se observa una relación disconforme en torno a las diferencias socioeconómicas y el estatus al que pertenecía cada ciudadano. Ese gusto por lo festivo y lo refinado es una muestra de la pervivencia de la clase alta y la vida europea, que, a la vez, es representada con gráficos en Variedades durante sus primeros dos años de edición (1908-1910). Por otro lado, se considera otra forma de valorar el teatro, pero sin 
exclusiones, en el apartado de "Espectáculos" (2 de enero de 1900). A través de esta, se hacen referencias a invitaciones frecuentes para que la gente acuda a los festivales y espectáculos que se efectuaban en los teatros. Uno de los más aludidos es el teatro Olimpo, que se promocionaba en varios diarios. Además, se halla la preferencia por pertenecer a la universidad, como fuente de conocimiento elitista. Esta noticia data del 4 abril de 1904, fecha en la que se divulga la nota periodística "En la Universidad. La apertura", basada en la designación de la ciencia como un valor universal, que era atribuida desde la institución hacia la sociedad. Evidentemente, la entidad académica a la que remite es la Universidad Nacional Mayor de San Marcos. Esta delimitación implicaba el rechazo a toda forma que suscitara algún tipo de pérdida o reducción del conocimiento (en ese entonces, prevaleció un interés por la raza). En Variedades (1908-1910), hay un artículo titulado "Notas de arte peruano", de José García Calderón, que está colocado por fragmentos en los primeros números publicados. En este, se aborda la relación existente entre el hombre y la naturaleza, la cual ocasiona una predisposición, ya que se adopta al indio como una raza inferior.

Así como se recurre a lugares a los que acudían las personas de clase alta, también, se prefiere la expectativa de integrarse a una vida más militarizada, pues la acotación constante al Real Felipe del Callao o la Escuela Militar de Chorrillos es un tema que se abarca a menudo en Variedades (19081910). En el diario La Prensa, se encuentra el texto "En la escuela militar de Chorrillos" (15 de enero de 1905), que detalla el valor de pertenecer a esa institución. A ello, se le junta todo lo vinculado con la aviación, como la referencia de la revista Variedades (1908-1910) a los aeroplanos, lo que induzca a lo patriótico (como los reiterados homenajes y celebraciones por las fechas cívicas del país), las fotografías de comisarios de la Policía y el tratamiento de combates marinos y los oficiales peruanos. Una particularidad en esta revista es que por momentos se ironizan la vida política y los políticos (se incorporan caricaturas).

Para concluir con ese tradicionalismo y explayar las diversas maneras de adquirir el conocimiento, la construcción utópica de la mujer en la sociedad limeña es persistente en ese periodo, tal como se demuestra en los artículos "La mujer en el Código y en la Sociedad I" (15 de octubre de 1904) y "La mujer en el Código y en la Sociedad III" (5 de noviembre de 1904), en los que se destaca el distanciamiento que ella debería tener con respecto a la idealización que se ha hecho de la misma desde la religión y la sociedad, con el objetivo de que se reconfigure su concepción a partir de una cosmovisión más liberal e independiente del hombre. Además, esa noción reincide en la publicación "La mujer en el Código y en la Sociedad II" (29 de octubre de 1904), ya que se busca su emancipación dentro de la libertad del pensamiento (esposa y madre libres). Una noticia de La Prensa, titulada "Hay que escuchar" (Nogales, 5 de julio de 1904), sostiene la importancia de la igualdad de género, en 
relación con la productividad y la inteligencia; sin resultar por eso con una actitud feminista, sino con la pretensión de que se oriente el tránsito hacia el progreso moral. En consecuencia, el autor postula que se debe atender a la mujer, porque de ella se obtendrá una innegable renovación de ideas. Estos temas son apoteósicos, puesto que se asocian con los tópicos que desarrolla Palma en Cuentos malévolos.

\section{El terror desde la concepción religiosa en el Perú (1900-1910)}

En síntesis, se manifiesta una lucha constante hacia la religión, a causa de la incredulidad de las Sagradas Escrituras, patentizada por el razonamiento y el cuestionamiento realizados sobre estas. Por ello, a continuación, mostraré las tres posturas que son persistentes durante el primer decenio del siglo XX: la neutral, a favor de la religión y la que se halla en contra.

En primer lugar, dentro de la posición neutral en función de la utilidad de la religión, en Variedades (2 de abril de 1910, pp. 420-424) se detectan los artículos "La semana santa", "La fiesta de los niños pobres en Miraflores" y "Los días santos en Chorrillos". En estos, no se emiten críticas ni favorables ni desfavorables: tan solo describe los sucesos habituales en los limeños durante esa celebración religiosa.

En segundo lugar, la perspectiva óptima es abarcada por la diversidad de creyentes. Se consideran muchas fiestas religiosas en múltiples publicaciones, a manera de crónicas, como se evidencia en "Fiestas religiosas" (Miró Quesada, 2 de enero de 1900, p. 707), en el que se exhibe una serie de iglesias, según horarios, para que la gente acuda a rendir una oración al Santísimo de distintas localidades con nombres de santos (Pedro, Carlos, Lázaro, Marcelo, Agustín, etc.). Hay artículos que emprenden homenajes al Viernes Santo, con imágenes de Cristo ensangrentado, junto con términos como Ecce homo o Mater dolorosa (Ulloa Cisneros, 20 de abril de 1905). En el diario La Prensa, prevalecen alusiones a celebraciones de esta índole, que se aprecian en "La fiesta religiosa de ayer" (23 de septiembre de 1903), que describe en específico elementos que santifican las celebraciones católicas, como las existentes en la provincia con la Virgen de las Mercedes, con la participación de la Iglesia. Los militares solían ejecutar sus actividades para honrar a las figuras religiosas (celebración por el día de la Inmaculada o a San Martín). Existe otro artículo titulado "Sección religiosa", subdividido por los apartados "Santoral" y "Cultos", en los que se hacen explícitas fundamentaciones sobre realizaciones eucarísticas que habrá en determinados lugares (Nazarenas, Desamparados, Merced, Descalzos, etc.). Por otro lado, se tratan máximas clericales y notoriedades con respecto al valor que asume el matrimonio religioso a diferencia del civil, como se cerciora en el Libre Pensamiento (30 de julio de 1904). Asimismo, menciona el desarrollo de misas y defunciones de 
santos, como las perpetradas hacia san Teodosio (Ulloa Cisneros, 10 de enero de 1905) o las dirigidas a quienes fenecieron en general, como se halla en una sección de La Prensa orientada al entierro de los muertos, "Defunciones" (25 de septiembre de 1903), en la que invitan a las personas para que vayan a esta celebración de algún pariente que quizá conocen; además de efectuarse procesiones, como la de Santa Rosa de Lima (Palma, 3 de septiembre de 1910, p. 1094). Se elabora un monumento a Cristo Redentor (Órgano de la Liga de Librepensadores del Perú, 30 de julio de 1904). Adicionalmente, se localiza una noticia extensa, con fotografías, destinada al Cristo de Velázquez, el padre Yeroví, el Pío X, las esculturas religiosas, la Biblia, la Virgen María y, de La Prensa (1904), unos santos, un tributo al Señor de los Milagros, como también un ejemplar dedicado a la Virgen de La Inmaculada, el monseñor Dr. Don Manuel Tovar (arzobispo de Lima), el Papa, etc.

En tercer lugar, como contraparte de la religión, a causa de las críticas y las polémicas originadas en otros ámbitos, se identifica el artículo de El Libre Pensamiento "Porvenir de las religiones" (18 de junio de 1904), en el que se plantea la religión como una forma de esclavización del espíritu por cuestiones absurdas e idólatras y falsos ritos. Se culpan sus dogmas por ser responsables de que produzca la guerra, al igual que la envidia, la crueldad y el asesinato. Estos patrones son cerciorados en la Biblia con la muerte de Abel por Caín, el rechazo del cristianismo por la refutable verdad del origen del universo y las concepciones ilusorias y erradas del amor, la felicidad, la sabiduría y la justicia. Más adelante, en "La bondad y justicia social", desde Locumba y con autoría de G. O. Pinto, se discrepa la capacidad de Dios para perdonar; pues, por medio de la religión católica, se asegura que las personas al fallecer pasen al Infierno, el Purgatorio o el Paraíso, mientras que, si existiesen el perdón y el amor, no debería haber esta división, ya que el pecado sería absuelto. La misma crítica se desarrolla acerca de la autorización del Todopoderoso que le otorgó a Satanás para ejercer el mal en la Tierra. Hay una crítica que persiste por parte de este periódico sobre la religión, como se observa en el artículo "Estúpido y abominable negocio de los padres salesianos en el Callao. Deificación y fraudes clericales", en el que los dos primeros párrafos de la nota son inconexos:

Es inaudito, inmoral, grosero, lo que pasa actualmente en el Perú con los hombres de hábito y coronilla. Cada día tenemos que denunciar los abusos y explotajes [sic] de los hombres de iglesia, cuya imaginación supera á [sic] los genios de la fantasía árabe en esto de engañar bobos y de sacar dinero de tutti [sic] quianti [sic] tenga la mala fortuna de llamarse católico, apostólico y romano.

La estafa religiosa cunde en el país de una manera alarmante. De todo saca partido el clerical insaciable en sed de lucro y de riquezas sin trabajar (Órgano de la Liga de Librepensadores del Perú, 6 de febrero de 1904). 
De modo similar, se prosigue en otro ámbito, el de la educación, como se demuestra en "Educación religiosa", en el que se critica directamente la enseñanza de la religión en las instituciones educativas:

Nuestros lectores recordarán que nos hemos ocupado de los inconvenientes, peligros y sensualidades de la educación religiosa en los colegios y escuelas, regentadas ó [sic] dirigidas por clérigos, monjas ó [sic] beatas francesas; y á [sic] fé [sic] que hemos probado con exactitud matemática, que la tal educación religiosa es una de las mayores calamidades que afligen a esta desgraciada república, víctima hasta hoy de la rapacidad é [sic] idolatría de los coronillas y sectarios del oscurantismo y de la barbarie católica, apostólica y romana (Órgano de la Liga de Librepensadores del Perú, 14 de mayo de 1904).

Se extrae un fragmento de un libro de Manuel Fernández Font con el título "La Iglesia Romana [sic] no es cristiana ni católica, es pagana" ( 2 de abril de 1904), en el que se fundamenta la idea de que Jesús no instituyó la Iglesia, sino que fue creación de los hombres. Encima, se burla de los rituales que usan los obispos y demás. Aparte de ese texto, posteriormente, se coloca la noticia "Dos sacerdotes criminales", con la intención de atacar a los miembros de la Iglesia, como también otros títulos sugerentes de El Libre Pensamiento como "El fanatismo religioso" (12 de marzo de 1904), "Barbaries del clericalismo" (13 de febrero de 1904) o "Inmoralidad de las procesiones de iglesia. Abolición y prohibición de ellas en la República de Bolivia" (13 de febrero de 1904). En esta última nota, se emplean hasta términos muy vulgares para desprestigiar las costumbres de los fieles: "En esas procesiones idólatras, estúpidas e irracionales, clérigos y frailes han embrutecido al pueblo á [sic] tal grado, que el vicio es allí la principal adoración y culto fetiquista". En son de burla, en una publicación de Variedades, se introdujo una imagen de Cristo crucificado, que se denomina "La erección de la Cruz" (18 de abril de 1908), cuadro de Van Dick, robado de la iglesia de Courtrai y recobrado poco después.

A su vez, se encuentra el artículo de Luis Navarro Neyra, "Los sacerdotes" (1 de mayo de 1905), que comprueba con información judicial y denuncias los abusos que cometieron algunos sacerdotes (violaciones y acosos a niños, además de asesinatos), con la pretensión de indagar la función de la Iglesia a nivel mundial. Igualmente, en "La voluntad de Dios" (González Prada, junio de 1905), se ironiza al Creador por el hecho de que existen en el mundo distintas formas de criminalidad y disposición que acepta la Ley, como la tortura en Roma, el garrote en España, la guillotina en Francia, la silla eléctrica y el linchamiento en EE. UU., junto con la horca en Rusia. 
Se manifiesta la alusión a las religiones. Por ejemplo, en el periódico El Libre Pensamiento, está el texto "Un templo masónico en Lima" (31 de diciembre de 1904), en el que se detalla su respectiva difusión, con la finalidad de enfatizar el progreso y la civilización en el país. Por otro lado, en esa fecha, existe otra propuesta al mostrarse críticas contra la religión. Sobre ello, se detecta la publicación "Espíritus mezquinos", en el que se cuestiona la imagen de los frailes y se destacan los crímenes ejercidos por el clericalismo. Adicionalmente, hay una provocación afianzada por los mensajes bíblicos. Verbigracia, en un breve discurso de El Libre Pensamiento titulado "Una nueva religión" (15 de octubre de 1904), se menciona la llegada de un "tercer Elías", un pastor llamado Dowié, de Chicago, quien solía repetir a sus seguidores que era el enviado de Dios.

Se conoce que Clemente Palma estaba más orientado a la postura en oposición a la religión. Esto lo demuestra también al escribir en "Carta literaria" (25 de abril de 1908) un comentario hacia la preferencia de Jesucristo en caso hubiera nacido en un lugar griego en vez de judío, por comodidad, economía y arte del mismo. Igualmente, plantea como prioridad la razón, y no la fe. Por otro lado, en parte de sus libros y sus cuentos, desarrolla la noción de combatir la doctrina de los creyentes por medio de su pensamiento ateísta (pues niega la idea de Dios), a causa de que, a través de esta cosmovisión, menoscaba la imagen de Cristo y la ridiculiza. Se puede observar una filiación de su ideología con la de Friedrich Nietzsche, sobre todo, con su texto El anticristo. Maldición sobre el cristianismo (2002 [1895], p. 4) en el que se postula que el cristianismo optó asociarse con lo débil, lo humilde y lo fracasado, motivo por el cual no era razonable y propio que el ser humano se basara en una fijación no proyectista desde esa degradada naturaleza. Ante esta situación, se erige el perfil del superhombre, fundamentado por Nietzsche en Así habló Zaratustra (2011 [1885], p. 5), como el que debe superarse. A pesar de ello, con esa concepción, se refuta el sentido de la existencia, ya que se asume la idea de que Dios ha muerto.

\section{Discusión}

A través del método de investigación de la documentación cualitativa de los diarios de La Prensa, El Comercio, El Peruano, Los Parias, La Campana, El Libre Pensamiento y la revista Variedades, junto con el proceso para efectuar una clasificación y un metaanálisis sobre los textos propios de la primera década del siglo XX, se evidencia que el concepto de terror permanece hasta el momento, tal como se pudo demostrar con sus alusiones y tratados heterogéneos en situaciones de la realidad y la ficción. Asimismo, es palmario el interés por establecer un nexo emocional entre autor-lector, merced a que la creación literaria y la redacción periodística oscilan en una documentación previa 
para plasmar ambientaciones y circunstancias verosímiles, con la volición de emerger una sensación particular del terror o una emoción similar. Cuentos malévolos procura emular esas descripciones horrorosas que se han ido consolidando en el discurso de la prensa. No es un referente ajeno a su contexto histórico ni tampoco es diferente de la producción literaria que se aprecia en el Romanticismo norteamericano por esa predilección por la muerte y ese suspenso generado por toda acción que supondría un final aterrador.

\section{Conclusión}

Mediante la documentación periodística, se obtuvo como resultado la construcción de un panorama que configura la percepción del terror durante el primer decenio del siglo XX. Primero, se comprobó que muchas de las noticias publicadas en los diarios trataban implícitamente sucesos tenebrosos que permitían percatarse de modalidades vinculadas con la noción investigada en este artículo. Por ejemplo, los crímenes fueron los que se incluían como elemento prioritario para destacar el terror. Segundo, el contexto bélico por el que atravesaba el país de formas directa e indirecta facilitó la comprensión del panorama que suscitaba un territorio en conflicto, ya que las amenazas, los atentados y la inseguridad ciudadana constituyen una atmósfera de intranquilidad (emoción que adopta el escritor peruano para sus relatos). Para terminar, la transgresión de la religión católica es una constante que representa a la época de ese momento, porque la filosofía y las ideologías que imperan buscan la racionalidad y la objetividad de sus discursos. Por consiguiente, surgen argumentos que captan la atención de ese lector remoto, con el propósito de que se generen sentimientos de repulsión y rechazo hacia lo que le ofrece un tipo de narrador totalmente desligado de la recepción que tendrá su cosmovisión ajena a la conservación de los códigos morales y tradicionales.

\section{Referencias}

Castro Oyanguren, E. (Dir.) (23 de septiembre de 1903). Cuestiones médicas. La alimentación de los tuberculosos. Las grasas. La glicerina. El azúcar. La Prensa. 
Castro Oyanguren, E. (Dir.) (23 de septiembre de 1903). La fiesta religiosa de ayer. La Prensa.

Castro Oyanguren, E. (Dir.) (25 de septiembre de 1903). Defunciones. La Prensa.

Castro Oyanguren, E. (Dir.) (1904). A última hora. Temblor terrible. Pánico general. La Prensa.

Castro Oyanguren, E. (Dir.) (23 de enero de 1904). No más canas. La Prensa.

Castro Oyanguren, E. (Dir.) (24 de enero de 1904). Cuestiones médicas. La Prensa.

Castro Oyanguren, E. (Dir.) (28 de enero de 1904). El robo en el Correo. La Prensa.

Castro Oyanguren, E. (Dir.) (2, 12, 14 y 29 de febrero de 1904). Varios. La Prensa.

Castro Oyanguren, E. (Dir.) (6 y 31 de marzo de 1904). Varios. La Prensa.

Castro Oyanguren, E. (Dir.) (24 de marzo de 1904). En broma. La Prensa.

Castro Oyanguren, E. (Dir.) (24 de marzo de 1904). Quería morir. La Prensa.

Castro Oyanguren, E. (Dir.) (10 de abril de 1904). Varios. La Prensa.

Castro Oyanguren, E. (Dir.) (14 de abril de 1904). El brujo de la calle de Saloon. La Prensa.

Castro Oyanguren, E. (Dir.) (27 de junio de 1904). Asesinos y falsarios. La Prensa.

Castro Oyanguren, E. (Dir.) (29 de agosto de 1904). Horrible tragedia. Una madre que come a su hija. Denuncia original. La Prensa.

Castro Oyanguren, E. (Dir.) (25 de septiembre de 1904). Cuestiones médicas. La Prensa.

Castro Oyanguren, E. (Dir.) (23 de octubre de 1904). Varios. La Prensa.

Castro Oyanguren, E. (Dir.) (3 y 8 de diciembre de 1904). La Prensa.

Fernández Font, M. (2 de abril de 1904). La Iglesia Romana no es cristiana ni católica, es pagana. EI Libre Pensamiento, VIII (410).

Gamero, J. (4 de febrero de 1905). Un caso inconcebible (de nuestro corresponsal). La Prensa, (715). Edición de la tarde.

González Prada, M. (Dir.) (junio de 1905). La voluntad de Dios. Los Parias, II (14).

González Prada, M. (Dir.) (octubre de 1905). Las víctimas de los accidentes. Los Parias, II (18).

González Prada, M. (Dir.) (octubre de 1905). Horrores en el Acre. Los Parias, I/ (18).

Miró Quesada, J. A. (Dir.) (2 de enero de 1990). Espectáculos. El Comercio, n. ${ }^{\circ} 23$.

Miró Quesada, J. A. (Dir.) (2 de enero de 1990). Fiestas religiosas. El Comercio, n. 23. 
Miró Quesada, J. A. (Dir.) (9 de enero de 1900). El día. Contra la tuberculosis. El Comercio.

Miró Quesada, J. A. (Dir.) (10 de enero de 1900). Inserciones. La conferencia del doctor patrón. El Comercio, (23).

Morales de la Torre, P. (15 de mayo de 1909). La muerte. Variedades, V (63), p. 259.

Morgan, P. (23 de septiembre de 1903). El pánico de New York. La Prensa.

Navarro Neyra, L. (1 de mayo de 1905). Los sacerdotes. Los Parias, II (13).

Neluz (30 de mayo de 1908). El espiritismo y la enquete de "Le Matin". Variedades, IV (13).

Nietzsche, F. (2002 [1895]). El anticristo. Maldición sobre el cristianismo. https://goo.gl/ueaa7v

Nietzsche, F. (2011 [1885]). Así habló Zaratustra. https://bit.ly/3af4FHX

Nogales, J. (5 de julio de 1904). Hay que escuchar. La Prensa.

Órgano de la Liga de Librepensadores del Perú (Dir.) (6 de febrero de 1904). Estúpido y abominable negocio de los padres salesianos en el Callao. Deificación y fraudes clericales. El Libre Pensamiento, VIII (402).

Órgano de la Liga de Librepensadores del Perú (Dir.) (13 de febrero de 1904). Barbaries del clericalismo. El Libre Pensamiento, VIII (403).

Órgano de la Liga de Librepensadores del Perú (Dir.) (13 de febrero de 1904). Inmoralidad de las procesiones de iglesia. Abolición y prohibición de ellas en la República de Bolivia. El Libre Pensamiento, VIII (403).

Órgano de la Liga de Librepensadores del Perú (Dir.) (12 de marzo de 1904). El fanatismo religioso. EI Libre Pensamiento, VIII (407).

Órgano de la Liga de Librepensadores del Perú (Dir.) (14 de mayo de 1904). Educación religiosa. EI Libre Pensamiento, VIII (416).

Órgano de la Liga de Librepensadores del Perú (Dir.) (18 de junio de 1904). Porvenir de las religiones. EI Libre Pensamiento, VIII (421).

Órgano de la Liga de Librepensadores del Perú (Dir.) (30 de julio de 1904). El Libre Pensamiento, IX (427).

Órgano de la Liga de Librepensadores del Perú (Dir.) (15 de octubre de 1904). Una nueva religión. El Libre Pensamiento, IX (438). 
Órgano de la Liga de Librepensadores del Perú (Dir.) (15 de octubre de 1904). La mujer en el Código y en la Sociedad I. EI Libre Pensamiento, IX (438).

Órgano de la Liga de Librepensadores del Perú (Dir.) (29 de octubre de 1904). La mujer en el Código y en la Sociedad II. EI Libre Pensamiento, IX (439).

Órgano de la Liga de Librepensadores del Perú (Dir.) (5 de noviembre de 1904). La mujer en el Código y en la Sociedad III. El Libre Pensamiento, IX (441).

Órgano de la Liga de Librepensadores del Perú (Dir.) (31 de diciembre de 1904). Un templo masónico en Lima. El Libre Pensamiento, IX (489).

Palma, C. (Dir.) (11 de abril de 1908). Almas que emigran. Variedades, IV (6).

Palma, C. (Dir.) (11 de abril de 1908). Otras almas. Variedades, IV (6).

Palma, C. (Dir.) (11 de abril de 1908). Los habitantes de Marte. Variedades, IV (6).

Palma, C. (Dir.) (18 de abril de 1908). La erección de la Cruz. Variedades, IV (7).

Palma, C. (25 de abril de 1908). Carta literaria. Variedades, IV (8).

Palma, C. (Dir.) (1 de agosto de 1908). Varios. Variedades, IV (22), p. 736.

Palma, C. (Dir.) (13 de febrero de 1909). En el mundo de las hadas y los duendes. Variedades, IV (50), pp. 1623-1624.

Palma, C. (Dir.) (26 de junio de 1909). Los últimos suicidios. Variedades, V (69), p. 393.

Palma, C. (Dir.) (25 de septiembre de 1909). Crimen por celos. Variedades, V (82), p. 711.

Palma, C. (Dir.) (25 de septiembre de 1909). El crimen Roccatagliata. Variedades, V (82).

Palma, C. (Dir.) (15 de octubre de 1909). El fusilamiento de Ferrer. Variedades, V (85), pp. 775-776.

Palma, C. (Dir.) (30 de octubre de 1909). Almas mudas. Variedades, V (87), p. 838.

Palma, C. (Dir.) (26 de febrero de 1910). El cometa Halley. Variedades, VI (104), pp. 271-272.

Palma, C. (Dir.) (2 de abril de 1910). La semana santa. Variedades, VI (109), pp. 420-424.

Palma, C. (Dir.) (2 de abril de 1910). La fiesta de los niños pobres en Miraflores. Variedades, VI (109), pp. 420-424.

Palma, C. (Dir.) (2 de abril de 1910). Los días santos en Chorrillos. Variedades, VI (109), pp. 420-424.

Palma, C. (Dir.) (3 de septiembre de 1910). Varios. Variedades, VI (131), p. 1094. 
Palma, C. (Dir.) (10 de septiembre de 1910). Espiritismo. Variedades, VI (132), p. 1137.

Palma, C. (Dir.) (17 de septiembre de 1910). El oro que huye. Variedades, VI, (133), pp. 1156-1159.

Palma, C. (2006 [1904]). Cuentos malévolos. Lima: Pontificia Universidad Católica del Perú.

Piphan (26 de marzo de 1910). Contra cometitas. Invento notable y de actualidad. Variedades, VI (108), pp. 389-390.

Ulloa Cisneros, A. (Dir.) (2 de enero de 1905). La Prensa, (655). Edición de la mañana.

Ulloa Cisneros, A. (Dir.) (10 de enero de 1905). Contradicciones y expectativas. La Prensa, (669). Edición de la tarde.

Ulloa Cisneros, A. (Dir.) (15 de enero de 1905). La visita de cárceles. La Prensa, (678). Edición de la mañana.

Ulloa Cisneros, A. (Dir.) (15 de enero de 1905). En la escuela militar de Chorrillos. La Prensa, (678). Edición de la mañana.

Ulloa Cisneros, A. (Dir.) (19 de enero de 1905). Varios. La Prensa, (654). Edición de la mañana.

Ulloa Cisneros, A. (Dir.) (22 de enero de 1905). Varios. La Prensa, (691). Edición de la mañana.

Ulloa Cisneros, A. (Dir.) (30 de enero de 1905). Los desesperados de la vida. Intento de suicidio en el hotel "Central". La Prensa, (706). Edición de la tarde.

Ulloa Cisneros, A. (Dir.) (4 de febrero de 1905). El caso sospechoso de peste bubónica. La Prensa, (715). Edición de la tarde.

Ulloa Cisneros, A. (Dir.) (4 de febrero de 1905). El cadáver de Dulanto abandonado. No existe Morgue en el Callao. La Prensa, (715). Edición de la tarde.

Ulloa Cisneros, A. (Dir.) (4 de febrero de 1905). Los que mueren de hambre. Un asesinato. La Prensa, (715). Edición de la tarde.

Ulloa Cisneros, A. (Dir.) (5 de febrero de 1905). La Prensa, (716). Edición de la mañana.

Ulloa Cisneros, A. (Dir.) (16 de febrero de 1905). Robo y persecución. La Prensa, (736). Edición de la tarde.

Ulloa Cisneros, A. (Dir.) (18 de febrero de 1905). Crimen por celos. Drama pasional. Dos puñaladas. Captura del criminal. La Prensa, (739). Edición de la mañana.

Ulloa Cisneros, A. (Dir.) (21 de febrero de 1905). Hallazgo de explosivos. Dinamita y bombas frente a la Intendencia. Sensación en el barrio. La Prensa, (746). Edición de la tarde. 
Ulloa Cisneros, A. (Dir.) (25 de febrero de 1905). Asalto y robo en la Magdalena Vieja. La Prensa, (753). Edición de la mañana.

Ulloa Cisneros, A. (Dir.) (28 de febrero de 1905). Escena sangrienta. Una puñalada. La Prensa, (758). Edición de la mañana.

Ulloa Cisneros, A. (Dir.) (28 de febrero de 1905). Captura de un bandolero. Sus hazañas. La Prensa, (758). Edición de la mañana.

Ulloa Cisneros, A. (Dir.) (28 de febrero de 1905). Accidente desgraciado. Un caballero lesionado. La Prensa, (758). Edición de la mañana.

Ulloa Cisneros, A. (Dir.) (1 de marzo de 1905). El fratricida. Narración verdadera. La Prensa, (760). Edición de la mañana.

Ulloa Cisneros, A. (Dir.) (1 de marzo de 1905). Un guardia criminal en la comisaría del 6. . Captura. La Prensa, (760). Edición de la mañana.

Ulloa Cisneros, A. (Dir.) (3 de marzo de 1905). Caso de locura. En un calabozo de la Intendencia. Comiéndose a un perro. La Prensa, (765). Edición de la tarde.

Ulloa Cisneros, A. (Dir.) (3 de marzo de 1905). Los crímenes en el campo. Mujer atropellada. La Prensa, (765). Edición de la tarde.

Ulloa Cisneros, A. (Dir.) (6 de marzo de 1905). Riña sangrienta. Tres heridas. La Prensa, (769). Edición de la mañana.

Ulloa Cisneros, A. (Dir.) (6 de marzo de 1905). Un ahogado. La desgracia de ayer. La Prensa, (769). Edición de la mañana.

Ulloa Cisneros, A. (Dir.) (6 de marzo de 1905). Riña de obreros. Una puñalada (de nuestro corresponsal en el Callao). La Prensa, (769). Edición de la mañana.

Ulloa Cisneros, A. (Dir.) (20 de abril de 1905). Varios. La Prensa, (850). Edición de la mañana.

Ulloa Cisneros, A. (Dir.) (26 de abril de 1905). Una cuchillada mortal. Crimen por idiotismo. Capturas. Atentado criminal en la Intendencia. La Prensa, (861). Edición de la tarde.

Ulloa Cisneros, A. (Dir.) (22 de mayo de 1905). Suicidio en la Maisón de Santé. Un enfermo que se ahorca. La Prensa, (908). Edición de la mañana.

Ulloa Cisneros, A. (Dir.) (20 de junio de 1905). Maltratos a una mujer. Ataque a la policía. Un guardia herido. La Prensa, (964). Edición de la mañana. 
Percepción del terror peruano entre 1900 y 1910: abordajes periodístico, político y religioso para el análisis de Cuentos malévolos de Clemente Palma

Ulloa Cisneros, A. (Dir.) (5 de julio de 1905). Crónica sangrienta. La Prensa, V (2910). Edición de la mañana.

Ulloa Cisneros, A. (Dir.) (12 de julio de 1905). La lepra y los leprosos (algunos casos típicos de lepra). La Prensa, V (2923). Edición de la mañana.

\section{Fuentes de financiamiento}

Autofinanciado.

\section{Conflictos de interés}

No presenta conflicto de intereses.

\section{Correspondencia}

tarmangani2088@outlook.com 